Accepted (peer-reviewed) version of article

It is authorized for self-archiving after an embargo period of 24 months.

Formatted by the author to enhance readability. 
Published in E. Bruner (ed.), Human Paleoneurology (Vol. 3, pp. 177-208). Springer Series in Bio/Neuroinformatics. Berlin: Springer.

\title{
Cognitive Archaeology and the Cognitive Sciences
}

\author{
Frederick L. Coolidge, Thomas Wynn, \\ Karenleigh A. Overmann and James M. Hicks ${ }^{1}$
}

\begin{abstract}
Cognitive archaeology uses cognitive and psychological models to interpret the archaeological record. This chapter outlines several components that may be essential in building effective cognitive archaeological arguments. It also presents a two-stage perspective for the development of modern cognition, primarily based upon the work of Coolidge and Wynn. The first describes the transition from arboreal to terrestrial life in later Homo and the possible cognitive repercussions of terrestrial sleep. The second stage proposes that a genetic event may have enhanced working memory in Homo sapiens (specifically in terms of Baddeley's multicomponent working memory model). The present chapter also reviews the archaeological and neurological bases for modern thinking, and the latter arguments are primarily grounded in the significance of the morphometric rescaling of the parietal lobes, which appears to have distinguished Homo sapiens from Neandertals.
\end{abstract}

Keywords Cognitive archaeology - Working memory - Enhanced working memory Parietal lobes - Intraparietal sulcus - IPS - Precuneus - Homo sapiens - Neandertals

Cognitive archaeology is an approach to understanding cognitive evolution that privileges the material record of past actions. Archaeological remains constitute the only direct evidence of past behavior that science possesses and, despite inherent biases in their deposition and discovery, provide an indirect avenue to the prehistoric mind itself. The challenges in approaching the prehistoric mind through the archaeological record are methodological, not epistemological. Archaeology can and does provide evidence for a variety of prehistoric activities, including tool making and use, subsistence, social arrangement in space, and even symbol use. From these, archaeologists have constructed an evolutionary sequence of hominin behavior and culture that parallels the evolutionary sequence of hominin fossils for 2.6 million years. With appropriate methods, this evolutionary record has tremendous potential for informing science about the cognitive abilities of hominin ancestors and near relatives.

There are several essential components in an effective cognitive archaeological argument (Wynn 2002, 2009a,b). First, it is necessary to have an explicit theory of cognition; common-sense categories such as 'abstract' or 'complex' are simply too vague to have much interpretive power. Worse, common-sense categories have rarely been defined and evaluated experimentally. In comparison, an explicit theory of cognition provides evolutionary analysis with well-defined cognitive categories and experimental/ethological evidence to support them. Second, the cognitive archaeologist must identify behavioral sequelae of these well-defined cognitive categories that would leave, potentially at least, an archaeological record. Ideally, this step would be supported by actualistic and experimental studies, a corroborative step that has rarely been taken. Third, the

\footnotetext{
${ }^{1}$ F. L. Coolidge - K. A. Overmann - J. M. Hicks

Psychology Department, University of Colorado, Colorado Springs, CO, USA

e-mail: fcoolidg@uccs.edu

T. Wynn

Anthropology Department, University of Colorado, Colorado Springs, CO, USA
} 
cognitive archaeologist must identify specific material attributes by which one can document the presence of this activity/cognitive ability in the past.

The archaeological record itself has several inherent biases that distort its perspective on the past and which must be considered when forming a cognitive archaeological argument. Very little of the material vestiges of past activity survives the ravages of time. Most organic material decays away quickly, and even bone disintegrates in many sedimentary contexts. In addition, the further back in time one looks, the less has been preserved. Thus, preservation and other natural processes of destruction have impressed a quasi-progressive pattern on the archaeological record; there is just a greater variety of evidence for more recent time periods. Dating is a perennial problem. In spite of a plethora of complex dating techniques, archaeologists of human evolution must often operate with only vague, geological-scale assessments of the age of important remains, a problem obviously shared with human paleontology. These biases are significant enough that it is often possible for the same evidence to be used in very different interpretations of the past.

Cognitive archaeologists must also eschew the traditional terms and concepts of Palaeolithic archaeology whenever possible. Terms such as 'Mousterian' or 'gravette' were defined over a century ago, when unilineal evolution and typology dominated prehistoric studies. They have no inherent cognitive implications. Indeed, unreflective use of such categories has been fairly rampant in recent archaeological attempts to document the evolution of the 'modern' mind. It is unfortunately impossible to banish these terms altogether. They are, after all, the common tongue of Palaeolithic archaeologists, and in this guise enhance academic communication. But it is possible, even necessary, to avoid using them as analytical tools and instead define appropriate terms and concepts using cognitive science.

Over the last 20 years cognitive archaeology has grown dramatically, and it is now impossible to summarize all of its contributions to understanding cognitive evolution. Here we will simply discuss three points in hominin cognitive evolution that appear to have been especially significant: the evolution of Homo erectus sensu lato 1.8 million years ago, the evolution of modern working memory capacity about 100,000 years ago, and the morphometric rescaling of the parietal lobes in Homo sapiens that is not evident in Neandertals. Note that we stipulate that our use of the term should be understood as Homo erectus sensu lato, or Homo erectus 'in the broad sense', the inclusive term for early African and Asian Homo populations. However, due to their relatively homogeneous cognitive and behavioral patterns, we will use the name archaic humans in the discussion that follows, and our initial use of the term Homo erectus sensu lato will be synonymous with our later use of the term archaic humans.

\section{The First Leap in Cognition: Transition from Tree to Ground Sleep in Archaic Humans}

As an example of the kinds of questions and issues that cognitive archaeologists address, Coolidge and Wynn (2009) proposed that there were two significant leaps in the evolution of human cognitive abilities. The first of these leaps was proposed to have occurred about 1.8 million years ago with the transition from life in trees to life on the ground in archaic humans, the second major species appearing in the Homo lineage. The first group of Homo species, often referred to as habilines after one of the varieties, Homo habilis, was heterogeneous in many anatomical respects but were included in genus Homo for two reasons: First, their brains were about $60 \%$ larger than those of the earlier australopithecines, and second, they appear to have been associated with the stone tools of the Mode 1 or Oldowan technocomplex. However, there is possible evidence of 
stone tool use in butchery by australopithecines at Dikika, Ethiopia at 3.39 million years ago (McPherron et al. 2010). This has been challenged by Domínguez-Rodrigo et al. (2010). Despite this apparent difference in behavior (which, along with their increased brain size, suggests differences in cognition), the habilines had the same general body proportions as the australopithecines, suggesting that despite their bigger brains, they still spent a considerable amount of time in trees (see Wong (2006) for a review of the evidence for and the debate over the amount of bipedality or arboreality in these early species).

By comparison, archaic humans, which appeared after 2.0 million years ago, have been associated with Mode 2 or Acheulean stone tools (bifacial handaxes and cleavers) and almost certainly slept on the ground. One of the most famous specimens of these archaic humans was Nariokotome, who appeared, even at the age he died (about 8-11 years old), to have attained a stature of about $160 \mathrm{~cm}$, and who might have attained an adult height of about 170-185 cm, although a more recent study estimates his adult height might have been only $163 \mathrm{~cm}$ (Graves et al. 2010). The muscle attachment on his long bones suggested he led a strenuous life, and his relatively long legs and narrow hips gave him a classic body type for both distance running and heat loss, ideal for life on the ground in hot, open habitats (Bramble and Lieberman 2004; Cachel and Harris 1998; Lieberman et al. 2009; Ruff 1991, 1993). This body type would have been very different from the smaller, tree-dwelling bodies of the australopithecines and habilines. Further, Nariokotome's endocranial volume was about 880 cc, and his adult endocranial volume might have been $910 \mathrm{cc}$, which makes him fairly representative since H. erectus crania range from a low of 700 cc in the earliest specimens to a high of over 1,200 cc in the latest (Antón 2003). His potential adult cranial volume therefore represents an absolute (but not relative) increase of nearly $50 \%$ compared to that of the habilines.

\section{The Archaeological Record for Archaic Humans}

The archaeological record for archaic humans boasts several evolutionary 'firsts', including movement out of tropical woodlands and out of Africa altogether. Most of these firsts have at least some cognitive implications. Here we will focus on just two: the advent of biface technology and developments linked to sleeping on the ground.

Before turning to bifaces, a brief description of pre-biface lithic technology is in order. Hominins began making stone tools over 2.6 million years ago (Semaw et al. 1997, 2003, 2009), and these tools and the sites where they were found have been important clues in paleoanthropology's attempts to understand the initial encephalization that occurred in the genus Homo (Schick and Toth 2006, 2009; Toth and Schick 2006, 2009). Various approaches to this Mode 1 or Oldowan evidence suggested that the advent of lithic technology marked a Rubicon in hominin evolution (Schick and Toth 2006). However, more formal cognitive archaeological analyses have yielded different results. Assessments from different cognitive theoretical perspectives-Piagetian (Wynn 1981) and cognitive neuroscience (Wynn 2002) — reveal that this earliest lithic technology was very apelike and therefore unlikely to have itself selected for larger brains or neural reorganization (e.g., Wynn et al. 2011). Neuroimaging research suggests that the attentional demands to Mode 1 tool creation may have been more related to perceptual-motor control rather than cognitive control (e.g., Stout and Chaminade 2007; Stout et al. 2000, 2008, 2011).

By comparison, the Mode 2 bifaces produced by archaic humans were clearly outside of the range of ape abilities. Bifaces were comparatively large stone tools produced by trimming 
bifacially around most or all of a large flake or core to produce handaxes and cleavers. The resultant tool has a continuous edge suitable for a variety of tasks, including butchery (Toth 1987). Several characteristics of bifaces have significant cognitive implications. Here we will focus on the imposition of shape and the curation of the artifacts; we will also briefly mention the implications for social learning.

The idea that archaic humans imposed a shape on bifaces has been challenged by several archaeologists (Davidson and Noble 1989, 1993; McPherron 2000; Noble and Davidson 1996), but to date, none have been able to provide convincing evidence that bilateral symmetry like that found on even the earliest bifaces could emerge as a regular, unintended consequence of producing flakes. Most authorities agree that the hominins intended that the artifacts be bilaterally symmetrical. This does not require that they possessed a detailed visual image of a target biface (a 'mental template' in archaeological jargon), but it does require attention to shape. Here again cognitive archaeologists' reliance on established theories has provided corroborating assessments. Wynn (2002) and later Hodgson (2009) pointed to an important and well-known feature of visual processing: Spatial information is processed through a dorsal stream that includes occipital and parietal lobe resources, but shape information is processed through a ventral stream of occipital and inferior temporal lobe resources.

To make a biface, the hominin had to coordinate both information streams, a feat unknown for apes. In their experimental/neuroimaging studies of biface manufacture, Stout and colleagues have been able to document use of neural resources in the manufacture of bifaces that were not evident in the motor/spatial procedures utilized in producing Mode 1 tools. In particular, they noted involvement of ".. the anterior intraparietal sulcus and inferior frontal sulcus, both in left hemisphere”' (Stout et al. 2011, p. 1334), areas that have been linked to the mirror neuron system and which are thus suggestive of social learning, which would have been critical to imparting the skills involved in biface manufacture. While there are undoubted cognitive differences between the brains of modern human research subjects and Homo erectus, studies such as those performed by Stout and colleagues enable us to make inferences about ancient hominin brain activity during tool manufacture. Thus, cognitive archaeology has identified significant evolutionary developments in the procedural cognition of archaic humans: abilities for coordinating previously separate neural resources and learning complex procedures by observation.

Curation refers to the habit of carrying tools from place to place as a regular component of a tool kit. Mode 1 tools, associated with the habilines, were rarely treated this way. Instead, raw material was carried to use sites where flakes were knapped, used, and discarded. Tool use was task specific and ad hoc (Toth 1985; Wynn 1981). However, some claim evidence for distant Oldowan hominin tool and material transport (e.g., Braun et al. 2008). It is relatively clear, however, that tools did exist as a category of object in the minds of archaic humans, and for the first time there was not only tool use but an idea of 'tool'. The neural resources for this development probably reside in the inferior temporal lobe, the same area that distinguishes 'animate' and 'inanimate' objects. The 'toolness' of bifaces had a couple of important long-term cognitive consequences. First, via extended cognition, the temporal (in the sense of time) continuity of bifaces may have enabled the bootstrapping (Malafouris 2008) of an expanded personal awareness beyond the ape range: The biface made yesterday is still here today and will be here again tomorrow, thus so will the knapper. This continuity also sets the stage for displaced reference (the ability to point to something not physically present) through the inherent indexical quality of the biface: The biface not only continues from yesterday, it could stand for its use yesterday or its potential use in the future. One of the puzzles 
of biface archaeology is why hominins made them and shared an idea of them throughout a significant temporal span and geographic distribution — over a million years and much of the Old World. A role as indexes in a prelinguistic social system might well account for this troubling pattern (versions of this argument have been explored by many scholars, most influentially by Donald 1991 and Kohn and Mithen 1999).

The skills involved in producing a biface and the persistence of the biface tradition over significant temporal and geographic spans imply that the skills were transmitted between individuals in some form of social learning (Mithen 1999; Stout 2002). Social learning has been observed in modern non-human primates, as for example, when chimpanzee juveniles learn to probe for termites by observing adults (McGrew 1992, 2004). Although bonobos have learned basic stone knapping, the more complex skills required for bifacial lithic reduction exceed their abilities, even after differences of anatomy (biomechanical constraints limit apes' ability to deliver stone knapping gestures as forcefully as humans can) and opportunity (apes lack the cultural intensity of humans) have been taken into account (Caruana et al. 2013; Savage-Rumbaugh et al. 2007). The key to learning and sharing ideas about shape (goal) and how to achieve it (process) is not communication as in language per se (since there is no evidence that archaic humans spoke), but the ability to come to a knowledge of what another understands to be appropriate (Wynn 1995). Social learning can take many nonlinguistic forms, including true imitation of motor procedures and less complex forms such as goal emulation, in which the novice not only models observed motor patterns but also constructs an individual understanding of the goal (Whiten and Byrne 1991; Whiten and Ham 1992). The skill inherent in the successful production of biface technology suggests that archaic humans likely mastered the technique through long periods of observation and repetition.

Bifaces exist today as direct ambassadors from a remote time in evolution when hominins first stepped away from an ape way of doing things and entered a new cognitive/cultural milieu that had no precedents. The development of biface technology was not the only significant cognitive 'first' associated with archaic humans. There must also have been changes in sleep patterns linked to sleeping on the ground.

\section{Challenges of Terrestrial Life}

The first challenge of life on the ground was the issue of predation. The australopithecines and habilines probably lived, mated, and played in trees, and slept in nests in trees, a lifestyle that would have protected them from predation. This supposition is made on the basis that tree nesting is a plesiomorphic characteristic in extant apes (even gorillas build nests but on the ground). As a plesiomorphic trait of living apes, it was most likely the behavior of the australopithecines. Life on the ground, however, would have required some other form of protection, either a dramatic increase in group size or use of fire, both of which have cognitive implications. Managing an increased number of social relationships would require several cognitive abilities, among them increased facility in facial recognition (for allies and enemies), memory for reciprocity in things like food sharing, and an expanded ability to manage simultaneous relationships (e.g., Dunbar 2003). Controlled use of fire, for which there is now evidence extending back 1 million years (Berna et al. 2012), would likely have selected for some increase in executive function capacity to ensure provisioning of fires and social cognition to coordinate fire maintenance (Twomey 2013). In addition, life on the ground appeared to have included a greatly expanded territorial range, estimated to have been about 260 square kilometers (about 100 square miles) for archaic humans 
(Antón and Swisher 2004; Antón et al. 2002), suggesting concomitant expansion of abilities in spatial cognition and memory.

Several anatomic changes in Homo erectus support the idea that this species spent more time on the ground and less in trees, including changes to upper body anatomy suggestive of reduced reliance on brachiation, as well as a reorganization of the inner ear consistent with the transition to ground life (Spoor and Zonneveld 1998; Steudel-Numbers 2006; Wong 2006). Further, the greater territorial range and overall geographic dispersal of Homo erectus also support the idea that the species had transitioned to a fully bipedal lifestyle that would have additionally entailed more time on the ground, including where it likely slept (Antón 2003; Antón and Swisher 2004; Antón et al. 2002).

However, some of the more interesting cognitive changes were linked to changes in sleep. Although there are at least four distinct stages of mammalian sleep, research tends to focus upon only two stages: Rapid-eye-movement sleep (REM or vivid dream sleep) and slow-wave (delta) sleep. All great apes have REM and slow-wave sleep, although REM varies from about 7-15 \% of their total sleep (e.g., Allison and Cicchetti 1976). Most monkeys, with whom modern humans share a more distant common ancestor than is the case with the great apes, also spend about 5-15 $\%$ of their sleep in REM. By comparison, modern human REM constitutes $25 \%$ of total sleep time, and it remains a relatively constant percentage across the lifespan after about 10 years of age has been reached (Ohayon et al. 2004).

Based in part on modern evidence of nest building in great apes, as noted previously, Sabater Pi et al. (1997) proposed that early hominins may also have nested in trees. Additional support for arboreal nesting among australopithecines and habilines rests on the evidence of hominin post-cranial anatomy, as climbing selects for more robust front limb features, longer arms relative to legs, a higher brachial index (length of forearm relative to upper arm), a more cranially (headward) orientated glenoid cavity, and curved fingers (Stanley 1992). Simply, their anatomy (particularly their arms) reflected an adaptation for arboreal locomotion (or brachiation). As all of the australopithecines and habilines retained these features of climbing anatomy, it is reasonable to conclude that these early hominins must have nested in trees and, by extension, retained an apelike pattern of sleep. Fruth and Hohmann (1996) proposed that nest building may have been a "great leap forward" in the evolution of cognition because the proximate functions of nests may have aided the transfer of information, that is, nests which are physically closer to each may help primates to warn nearby nesting primates of impending danger as well as transmission of other types of signals. Further, they proposed that the protection and stability provided by sleeping in nests may have increased the proportions REM sleep and slow-wave, which in turn may have helped to establish and consolidate memories.

By comparison, archaic humans (as is the case in Nariokotome) possessed relatively short arms compared to the long, brachiation-adapted arms of the australopithecines and habilines, anatomy that suggests archaic humans had transitioned to life on the ground, a lifestyle that not only entailed new forms of protection, social organization, and technologies but also improved the quality and quantity of sleep. Full ground sleep would have preserved the general integrity of the sleep period (e.g., sleep became less fragmented because it was less subject to the danger of falling and disruptive vagaries such as strong breezes, bad weather, etc.), further aiding increases in slowwave and REM sleep. In addition, there may have been three specific evolutionary benefits for cognition from sleep on the ground: (1) threat simulation and priming, (2) creativity, and (3) procedural memory consolidation and enhancement. 
Threat simulation and priming. Revonsuo (2000) has argued that the waking lives of most dreamers were unlikely to have high levels of daily threat, especially attacks by wild animals. He hypothesized that the dreamers relived archaic dream themes, particularly ones that would simulate the real dangers of the ancestral environment, including falling, encounters with natural disasters and threats posed by strange people and wild animals. He reasoned that through natural selection, dreaming came to have the function of threat rehearsal, threat perception, and threat avoidance. The selective advantage would come from a dream theme repetition that would enhance and prepare waking threat-avoidance skills, which experimental psychologists call priming. A study by Malcolm-Smith and Solms (2004) provides some support for Revonsuo's hypothesis. About $9 \%$ of a sample of college students reported realistic physical threats in a dream and about $3 \%$ reported a realistic escape response in the face of the threat. Although these percentages on the whole are rather low, it does demonstrate that threats and escape from threat themes are not rare nor absent in dreams. Revonsuo and others (Revonsuo and Valli 2000; Valli et al. 2005) thus viewed the present dreamproduction system as one that simulates threatening events in the ancestral environment while also making the dreamer more ready (priming) for an actual waking threat.

Franklin and Zyphur (2005) broadened Revonsuo’s hypothesis and proposed that dreaming may not only serve to simulate ancestral threats but may also serve as a more general rehearsal mechanism for scenarios encountered in daily life, subsequently and positively influencing waking encounters. Such a mechanism would facilitate decision making without significant influence from conscious awareness or language. If this hypothesis is correct, dreaming may have played a more important role in Homo evolution prior to the advent of language. Physiological evidence for the hypothesis comes from the activation during REM sleep of the ventromedial prefrontal cortex (PFC), amygdala, and anterior cingulate cortex, which mediate some of the affective executive functions and are thought to play a strong role in social and interpersonal decision-making and evaluations (e.g., Gazzaniga et al. 2013).

Creativity. There is extensive anecdotal evidence for a link between creativity and dreaming. Artists and musicians who have claimed inspiration from dreams include Durer, Goya, Blake, Rousseau, Dali, Mozart, Wagner, and Billy Joel, among many others. Perhaps most famously, Samuel Taylor Coleridge claimed that his poem Kubla Khan came to him in a dream. Russian chemist Dmitri Mendeleyev said that he conceived of the periodic table in a dream, and French chemist Friedrich Kekulé claimed that the circular structure of the benzene molecule came to him in a dream (see Hartmann 1998; Van de Castle 1983 for a more complete discussion of dreams and creative thinking). In a survey of contemporary mathematicians, over $50 \%$ reported that they had at least once solved a mathematical problem in a dream (Krippner and Hughes 1970). Indian mathematician Ramanujan averred that a form of the goddess Lakshmi gave him many mathematical ideas in his dreams.

Empirical evidence for sleep and creative problem solving comes from a study by Wagner et al. (2004), who gave human participants a cognitive task that required learning stimulusresponse sequences (which they deemed an implicit procedural memory task) where improvement, as measured by reaction time, was evident over trials. Participants could improve abruptly if they gained insight into a hidden abstract rule. Twice as many participants who slept became aware of the hidden rule than those who stayed awake, regardless of time of day. The authors postulated that the participants' greater insight was not a strengthening of the procedural memory itself but involved a novel restructuring of the original representations. Wagner et al. suspected that cell assemblies representing newly learned tasks were reactivated by the hippocampal structures during 
sleep and incorporated by the neocortex into preexisting long-term memories. They hypothesized that this process of incorporation into long-term storage formed the basis for the remodeling and qualitatively different restructuring of representations in memory.

Visuospatial, autobiographical, and procedural memory consolidation and enhancement. Winson (1990) presented empirical evidence for REM's role in memory consolidation with rats. He demonstrated that a theta rhythm $(6 \mathrm{~Hz})$ arises from the hippocampus associated with exploratory behavior. Because exploratory behavior appears critical to their survival, Winson reasoned that one purpose of REM sleep might be the strengthening and consolidation of visuospatial (procedural) memories. There is also substantial empirical evidence for the enhancement of various kinds of procedural memories in human sleep. Karni et al. (1994) demonstrated consolidation-based enhancement on a procedural visuospatial discrimination task. Stickgold et al. (2000) used the same task and found that the consolidation enhancement was dependent only on the first night of sleep following acquisition and that learning was correlated with both the amount of slow-wave sleep and the amount of REM sleep. Again using the same task, Gais et al. (2000) concluded that consolidation-based enhancement might be instigated by slow-wave sleep, whereas REM and Stage 2 may solidify and add to the enhancement effect, but that slow-wave sleep was a necessary component.

As a function of these sleep changes, and by means of the phenomenological contents of sleep (dreaming), (1) early archaic humans may have been primed to escape and avoid threatening events in the their waking environments and may have rehearsed social scenarios; (2) the contents of REM sleep may have promoted creativity and innovation; and (3) sleep changes may have aided autobiographical (episodic), visuospatial, and procedural memories, which include memories for motor skills, visuospatial discriminations, and spatial locations, without any further acquisition or practice. It is also important to note that recent fMRI and polysomnography studies of sleeping humans have also suggested that both REM and slow-wave sleep may have independent but complimentary roles in emotional memory processing (Cairney et al. 2014). Further, Tononi and Cirelli (2014) have proposed a synaptic homeostasis hypothesis which purports that during sleep spontaneous neuronal activity renormalizes synapses and restores synaptic strength as well as promotes neuronal homeostasis. One net effect of this process is that memories may be strengthened and new associations may be created. These findings and assertions serve to support our contentions that the tree-to-ground sleep transition had a potentially profound effect on the lives of archaic humans.

\section{The Second Leap in Cognition: Expanded Working Memory in Homo sapiens}

Recently, paleoanthropologists (e.g., Henshilwood et al. 2004; Henshilwood and Dubreuil 2009) have made several claims for symbolic behavior and 'fully syntactical language' based on the presence of artifacts such as shell beads in South African Middle Stone Age sites. Botha (2008, 2012), Wynn (2009a), and Wynn and Coolidge (2010) have noted that these claims lack adequate bridging arguments, that is, the putative steps that tie these artifacts to symbolic behavior to fully modern language. As we noted earlier, to be persuasive, such linking arguments must articulate with well-established theories or models of cognition. Working memory is such a model. It was initially proposed in 1974 by experimental psychologists Alan Baddeley and Graham Hitch and has dominated and stimulated contemporary memory research over the past four decades (Baddeley 2001, 2007; Baddeley and Hitch 1974; Nota bene: The concept of working memory has 
also been used in a more narrow sense, and its narrow use does not imply Baddeley's multicomponent model). Importantly, various psychometric measures of working memory capacity have been found to be correlated with a variety of critical cognitive abilities, including reading comprehension, vocabulary learning, language comprehension, language acquisition, secondlanguage learning, spelling, storytelling, logical and emotional reasoning, suppression of designated events, certain types of psychopathology, fluid intelligence, and general intelligence. The relationship with fluid intelligence is an important one because fluid intelligence measures an ability to solve novel problems. It appears to be less influenced by learning and culture and more influenced by some feral or inherent talent to figure out solutions to new problems. Thus, Baddeley's model, which incorporates the executive functions metaphor, is a natural heuristic for inquiries into the evolution of modern thinking.

Baddeley’s multi-component Working Memory model currently consists of a (1) central executive, (2) phonological storage, (3) visuospatial sketchpad, and (4) episodic buffer. Baddeley's idea of a central executive is virtually synonymous with concepts associated with the literature on executive functions of the frontal lobes, concepts that remain primarily within the discipline of neuropsychology, whose suppositions generally (but not exclusively) rely upon inferences based on brain-damaged patients. Briefly, the central executive directs attention to complete tasks based on short-term and long-term goals. The central executive does so by attending to appropriate tasks at hand which are consonant with short- and long-term goals, inhibiting irrelevant stimuli and distractions, and making decisions based on sequenced plans of actions. The central executive also directs two subsystems, the phonological loop and the visuospatial sketchpad. The phonological loop contains two elements, a short-term phonological store of speech and other sounds, and an articulatory loop that maintains and rehearses information either vocally or subvocally. The visuospatial sketchpad incorporates the maintenance and integration of visual ("what", information like objects) and spatial ("where" information like location in space) elements and a means of refreshing it by rehearsal. Finally, the episodic buffer serves as a temporary memory system for the central executive, and according to Baddeley (2000), integrates and stores information from the other two subsystems.

A core component of Coolidge and Wynn's (2009) second major leap in cognition is Baddeley's central executive. Baddeley and others (e.g., Baddeley and Logie 1999; Miyake and Shah 1999; Osaka et al. 2007) view the central executive as consisting of varying functions, including attention, active inhibition, decision making, planning, sequencing, temporal tagging, and the manipulation, updating, maintenance, and integration of multimodal information from the two subsystems. Importantly, the central executive also takes control when novel tasks are suddenly introduced, and one of its most important functions is to override pre-existing habits and to inhibit prepotent (previously well learned) but task-inappropriate responses. The central executive also takes control when danger threatens and task-relevant decisions must be made.

Most of these central executive functions have been ascribed neurally to the PFC (Lezak 1982; Kane and Engle 2002) based on a wide variety of evidence including single-cell firing, brainimaging, and neuropsychological studies. Collette and Van der Linden (2002) have also postulated, based on empirical brain imaging studies, that the central executive component of working memory recruits not only frontal areas but also parietal areas (Koenigs et al. 2009, proposed that parietal functions for spatial representation and attentional allocation support the manipulation of information that differentiates working memory from other forms of memory). Collette and Van der Linden conclude that its operation must be understood as an interaction of a network of cerebral 
and subcortical regions, as have Hazy et al. (2006). The latter proposed a complex model, called PBWM (PFC, basal ganglia working memory model), which views the PFC as critical in maintaining representations of an individual's perceptions in the broadest sense, which are dynamically updated and regulated by reinforcement learning systems that themselves are based on chemical neurotransmitters (primarily dopamine) activated by the basal ganglia and the amygdala. They further propose that these learning systems can be modified, and thus, can learn to control themselves and related brain areas in order to act in a task-appropriate manner. Thus, the central executive can also be viewed as an emergent property of the interactions between the PFC, the other lobes of the brain, subcortical structures, and the cerebellum (e.g., Vandervert 2009, 2011).

From an evolutionary perspective, it appears obvious that these major components of the working memory model are ancient. Organisms have been making decisions and inhibiting responses (even if simply because of behavioral conditioning) for hundreds of millions of years. The phonological component of working memory may itself have antecedents in primate evolution going back 40 to 60 million years (e.g., Aboitiz et al. 2010). The separate visual and spatial abilities may also have a deep evolutionary history, but their integration in the working memory model may be unique to humans. Also, unique to humans is the binding of the contents of the visuospatial sketchpad to elements in phonological storage. Further, humans through rehearsal and/or arousal can relegate these bound elements to long-term memory. Indeed, humans regularly coordinate visual and spatial information in working memory. The archaeological evidence from stone tools, primarily handaxes, suggests the ability to coordinate visual and spatial information, and in all likelihood store the information in long-term procedural memory, was in place by 1.8 million years ago (Wynn 2002).

One component of the working memory model that might be the key feature of fully modern Homo sapiens is the episodic buffer. Baddeley initially described the central executive as largely attentional in nature without its own storage capacity, but he eventually realized that it also must have some way to store information independent of the subsystems. He thus proposed the episodic buffer as the storage component of the central executive. He endowed the episodic buffer with the ability to bind and integrate the two subsystems, the phonological loop and the visuospatial sketchpad, and also traces from long-term memory, via a multimodal code. By attending to multiple sources of information simultaneously, the central executive is able to create models of the environment that can themselves be manipulated to solve problems and even plan future behaviors and alternative strategies, so that if a plan fails, another may be chosen or generated.

The episodic buffer of working memory may also play a role in episodic memory (Tulving 2002). An episodic memory is a coherent, story-like reminiscence for an event, often associated with a specific time and place, and a feeling signature. A reminiscence will include specific knowledge and details, but its recall and subjective experience will be psychologically and neurologically different from the recall of such semantic components alone. Further, Tulving proposed the term 'autonoesis' to refer to the ability to form a special kind of consciousness in which individuals become aware of the subjective time in which past events happened:

This awareness allows autonoetic creatures to reflect on, worry about, and make plans for their own and their progeny's future in a way that those without this capability possibly could not. Homo sapiens, taking full advantage of its awareness of its continued existence in time, has transformed the natural world into one of culture and civilization that our distant ancestors, let alone members of other species, possibly could not imagine (Tulving 2002, p. 20). 
While there is evidence of autonoesis in other species - for example, blue jays and chimpanzees (Clayton et al. 2003; Martin-Ordas et al. 2013) — humans may be unique in using autonoesis to form hypotheticals (i.e., comparing imagined with real scenarios), communicate alternative courses of action through language, and anchor their reflections, worries, and plans in material culture (Malafouris 2013).

There is growing evidence that Baddeley's episodic buffer and Tulving's episodic memory are both highly dependent upon neurons in the precuneus, a superior medial portion of the parietal lobes (e.g., Cavanna and Trimble 2006) that integrates higher-level cognitive processes (e.g., visuospatial processing, attention, self-consciousness, episodic memory) and which is associated with morphological variation in parietal shape in extant humans (Bruner et al. 2014). The precuneus may also serve as the neurological substrate for the ability to construct future scenarios, an ability known as prospective memory (Addis et al. 2007). Suddendorf and Corballis (2007) have suggested that if episodic memory functioned merely to record and subsequently reproduce events at a future date, then a reproductive memory system would seem more appropriate. They also argued that the primary role of episodic memory was the construction of future simulations. They suggested that prospective memory is a process whereby both semantic and autonoetic information populate a conceptual spacethe episodic buffer - enabling the central executive to manipulate the information to simulate different scenarios in an attempt to predict the future. This would have endowed Homo sapiens with the ability to model alternatives, increasing the likelihood that behavioral choices would achieve desired outcomes. This constructive creativity would have enhanced abilities for planning, improvising, and innovating, improving adaptive success (Ambrose 2010).

\section{Archaeological Evidence for Improvements in Working Memory}

Over a decade ago, Coolidge and Wynn (2001) argued that the archaeological record could potentially document the evolution of modern executive functions. As discussed at the beginning of the chapter, the second essential step in a cognitive archaeological analysis is identification of activities that clearly required the cognitive ability under investigation. So, what activities might act as reliable indicators of a modern executive reasoning ability? Coolidge and Wynn focused on specific cognitive abilities linked to executive control: sequential processing, response inhibition, and planning over distance and time. Specific activities requiring these abilities and which are potentially visible in the archaeological record include: reliable technical systems, such as traps, that require labor investment up front for a higher return in the future (response inhibition and sequential processing); managed foraging systems that plan over months and years (response inhibition and planning over long distances and time); voyages of colonization (planning over long distances and time); and use of algorithmic devices (simultaneous processing). However, it is important to note that many activities that may be deemed impressive do not necessarily require advanced working memory. Mode 2 bifacial handaxes and the later Levallois technique may be good examples of impressive technologies that do not require enhanced working memory.

One of the functions of the central executive is the ability to 'tag' memories in sequential time. Thus, sequential memory is an essential ability for any task (either declarative or procedural) requiring a complex linkage of steps. Recently Lombard and Haidle (Lombard and Haidle 2012) have described the complex chaîne opératoir required for the production of bows and arrows, for which there is now persuasive evidence dating back to about 64,000 years ago in the South African Middle Stone Age. The process required coordination of several discrete subprocesses, many 
executed at different times in different places, into an overall plan of action that is similar in all important respects to the plans of action used by modern craft artisans (Keller and Keller 1996). Wadley and colleagues (Wadley 2010; Wadley et al. 2009) have provided archaeological and experimental evidence for the production of the compound adhesives used in the process. It required a complex sequence of steps that included the use of fire to transform the acacia gums, beeswax, and ochre into a workable glue. This sequential process also required that the artisans monitor several conditions simultaneously, which required shifting attention, another executive function. A bow and arrow system is an example of what Bleed (1986) has termed a 'reliable' weapon system, one that requires a great deal of time and effort to produce 'up front', but which is more reliably deadly when put to use.

Another even stronger signature for advanced executive functions are tasks involving inhibition, in which immediate gratification and prepotent actions are delayed. Agriculture, especially cultivation, planting, storage, herd culling, and so on, requires such inhibition; indeed inhibition is probably the key cognitive prerequisite for agriculture (Sherratt 1997). But inhibition is not limited to agricultural systems; it is also a component of almost all recent hunting and gathering groups, who 'manage' their food supply by avoiding use of some resources in some seasons and by landscape alteration to increase future yields (Wynn and Coolidge 2003). Coolidge and Wynn (2001) have also argued that facilities (e.g., Oswalt 1976) such as remote traps may be considered technologies of inhibition, and these technologies were arguably also present in the South African Middle Stone Age (Wadley 2010).

Roebroeks et al. (1988) have cited organization and planning as a synonym for foresightful thinking. One of the most notable examples may be the colonization of the Sahul (i.e., New Guinea, Australia, and Tasmania). Davidson and Noble (1993) and Klein (2000) also have emphasized this seafaring colonization as a marker for modern behavior, and it has been dated to about 45,000 years ago (O’Connell and Allen 2004). Colonization of the Sahul required use of watercraft and a journey over the horizon (at that time, the Australian landmass was not visible from Timor, the farthest eastern extension of the Sunda shelf). While Davidson and Noble argued that this task required conceptual thinking based on language, we suggest that it required executive functions. Watercraft themselves are a multi-step technology requiring sophisticated sequential memory, and their use requires the kinds of organization and planning that are characteristic of modern executive functions.

As an archaeological example suggestive of episodic memory, Wynn and Coolidge (2012) noted the series of 35,000-year-old burials at the site of Sungir, Russia, a massive settlement covering nearly 5,000 square kilometers. In the main burials were found the remains of an adult male Homo sapiens about 60 years old and two children, possibly a boy about 13 and a girl about 8. The remains were found with thousands of ivory beads that were either necklaces or sewn onto their clothing; the man's arms were encircled by bracelets of painted mammoth ivory. The children were buried head-to-head. The boy had been given a painted stone pendant that probably hung from a string or leather rope around his neck; he also had painted ivory mammoth arm bracelets, a beaded cap with fox teeth, and a belt with about two hundred and fifty fox teeth. He wore an ivory pendant in the shape of an animal, an ivory sculpture of a mammoth was on his shoulder, and he had ivory ornamental disks. He was buried with an ivory hunting spear, which might have been tapered to the length of his body. The girl had a similar but smaller ivory spear and was buried with more than five thousand ivory beads.

The Sungir burials appear very different from the roughly contemporary Neandertal burials at La Ferrassie and Kebara, where the remains were neither accompanied by grave goods nor 
carefully composed in their final resting postures. Perhaps the most interesting features of the Sungir burial, however, are the ivory hunting spears. Because ivory is soft, such spears may not have been ceremonial rather than intended for real hunting, implying that the Homo sapiens may have been thinking about a life after death and perhaps hunting in the afterlife, an example of autonoetic thinking (Tulving 2002).

\section{Enhanced Working Memory}

Coolidge and Wynn (2005) argued that these essentially modern executive functions were powered by an enhancement of working memory capacity, attributed to a genetic or epigenetic event that occurred in all probability within the last 200,000 years. As a neural event/mutation, there are several possibilities. There could have been a general, non-domain specific enhancement of working memory capacity, or, alternatively, there might have been enhancements to specific components of working memory, improving their attendant functions. The difficulty with investigating the first alternative, particularly within an experiment, is that measures of working memory capacity must always be operationalized within a specific context (e.g., verbal, visual, or spatial, all of which are domain-specific); thus, measures of working memory capacity are biased by the nature of the measurement and can only hint at the nature of non-domain specific working memory capacity. With regard to the second alternative, an enhancement of one of working memory's components, there are as many candidates as there are components in the model, and probably more. We have already noted the importance of the inhibitory function of the central executive because the ability to inhibit prepotent but task-inappropriate interference is critical to the attainment of goals. Inhibition may not only be critical to tasks at hand, but also to successful interactions in social interactions. Inhibition may have been critical to diplomatic speech, and thus, interactions and trade with different groups (Coolidge and Wynn 2012). Inhibition may also have been critical to successful social interactions within a group, as a lack of inhibition might have resulted in injurious behaviors to self or others as a result of reckless impulsiveness (i.e., antisocial behavior traits or borderline personality disorder traits; see Segal et al. 2006).

A third candidate for the basis of enhanced working memory is phonological storage capacity. It is especially provocative that phonological storage capacity is significantly related to general intelligence and fluid intelligence, although to a lesser extent than some other measures of working memory capacity. Adults who have greater phonological storage capacity have also been found to do better on verbal tests of intelligence and score higher on measures of verbal fluency; they also do better on retroactive and proactive interference tasks (Kane and Engle 2002). Children with greater phonological storage capacity had a larger vocabulary, produced longer utterances, and demonstrated a greater range of syntactic construction (Adams and Gathercole 2000). Furthermore, some linguists have touted recursion as the key to modern language (Coolidge et al. 2011; Hauser et al. 2002; Reuland 2005). Recursion is the grammatical rule that produces certain kinds of embedding or hierarchical sentence construction, but it requires adequate phonological storage capacity for its execution. It is also possible that enhanced phonological storage capacity, coupled with recursive abilities, allowed longer sentences with greater informational complexity, an obviously adaptive evolutionary consequence (Coolidge 2007).

A fourth possibility for the more specific nature of enhanced working memory is an expansion of the visuospatial sketchpad and the episodic buffer. As noted previously, there is strong adaptive value in the ability to simulate the future, coupled with its potential consequences 
for innovation and creativity (e.g., Tulving 2002). This anticipation and simulation of future events has been labeled constructive episodic simulation or more simply, prospective memory (e.g., Addis et al. 2007). Simulation allows the creation of various future events, often drawn upon the experience of past events, and allows them to be flexibly rearranged in order to simulate the future options. Also, as noted previously, prospective memory has a firm neural basis in the precuneus, and that area has undergone a dramatic expansion in Homo sapiens compared to Neandertals (e.g., Bruner 2004, 2010). Empirical research in the past decade has also substantiated the role of the precuneus in a sense of self consciousness, sense of self, autobiographical memory, and egocentric memory (Cavanna and Trimble 2006; Land 2014; Lou et al. 2004).

A final possibility for enhanced working memory is partially based on the provocative work of Weaver (2005) who found the cerebellum ratio (cerebellum to cortex) in Homo sapiens to be significantly greater than that of Neandertals. The cerebellum has been traditionally thought to play a major role in the control of fine motor movements. The cerebellum also possesses a high neuronal density. Of the 100 billion neurons thought to comprise the human brain, approximately $70-80 \%$ are in the cerebellum. It is also known that all lobes of the brain project to the cerebellum (by way of the pons) and then project back to all portions of the cortex. Vandervert (2003a,b, 2009) and others (e.g., Koziol et al. 2010; Vandervert et al. 2007) have proposed an important cognitive function to the cerebellum. The multi-component working memory system appears to interact with the cerebellum such that initial plans and models for thinking and action arising from the cortex are continuously fed to the cerebellum and back to the cortical areas underlying working memory, and thus, initial plans and models are refined and made more efficient. Vandervert and others have concluded that this cerebellar feedback system may be the neural basis for creativity and innovation. De Smet et al. (2013) have recently presented evidence for the cerebellum's role in language, higher level cognitive processing, and emotional processing. However, Weaver's claim is not without criticism, as some paleoneurologists doubt whether the cerebellum can be validly measured in endocasts.

\section{Another Important Change: Morphometric Rescaling of the Parietal Lobe}

Morphometric rescaling of the parietal lobe and concomitant expansion of its functions may be one of the most significant changes in the evolution of the human brain, implicated in such matters as the ability to exploit larger territories and the development of symbolic culture. Parietal change in Homo sapiens consists of a anterior widening and vertical expansion not seen in other hominins, and may be the neuroanatomic characteristic that truly differentiates Homo sapiens from related species (Bruner 2003, 2004, 2010; Bruner and Holloway 2010; Bruner et al. 2003, 2011). Parietal rescaling has been associated with sequelae of globularization, reorganization of neural connectivity between and within various brain regions, and enhanced parietal functioning (Bruner 2004, 2010; Bruner et al. 2003). Also, it is important to note that proportions of the frontal lobes have been described by Bruner and Holloway (2010) in modern humans and Neandertals and that changes in the frontal lobe areas are frequently associated with parallel changes in the parietal regions (Bruner 2010).

Functions supported by the parietal lobe include the analysis of relationships of space, time, and number; integration of visuospatial and sensory information, including the location of the body in space; planning and execution of motor sequences; creation of 'inner space' representations of external space; and critical language functions, including abilities for comprehending speech and 
metaphor (Bruner 2004, 2010; Chiappe and Chiappe 2007). The intraparietal sulcus (IPS) is a parietal region of particular interest because of its implication in a wide variety of cognitive functions, including motor planning, perceptual-motor coordination, various forms of attention, numerosity and calculation, visuospatial working memory, spatial representation, spatial coordinate transformation, mental rotation, aspects of long-term memory and language, and intent interpretation (e.g., Bruner 2010; Orban 2011; Orban and Caruana 2014; Peeters et al. 2009, 2013). Imaging studies have demonstrated IPS activation during movements involving both the hands and spatial judgments (e.g., pointing, reaching, and grasping); the tactile manipulations of objects; and observations of hand movements made by others or objects associated with manual manipulation, such as tools and toolmaking (Culham and Kanwisher 2001; Stout and Chaminade 2007). With regards to visuospatial integration, it may be important to note that one critical function of the IPS is hand-eye coordination. As such, eyes and hands may be considered portals, which aid the brain's interface with its environment and support the simulation of the environment (see Bruner 2010; also see Ogawa et al. 2010). Holloway (1996) cited strong natural selection for behaviors associated with parietal functions, particularly associative functions integrating visual, auditory, and spatial information with sensorimotor activity. Enhanced parietal functions would have included extended spatial abilities, demonstrated archaeologically by an increased ability to navigate larger geographic areas successfully and remember specific resource locations (Holloway 1996).

Lacking the parietal expansion that characterized Homo sapiens, Neandertals may have been particularly disadvantaged in this regard, an assessment that is supported when the archaeological signatures of the two species are compared. Neandertal sites tend to contain fewer exotic raw materials than those of Homo sapiens, which suggests that in general Neandertals may have exploited smaller territories than Homo sapiens did (Fernández-Laso et al. 2011; García-Antón et al. 2011; Spinapolice 2012). An explanation consistent with differences in parietal lobe functioning would be that Neandertals found it more difficult to navigate large landscapes as a function of a more limited ability to resolve spatial relationships and remember landmarks. Improvements in the visual representation of shape, sensorimotor control of the fingers, and the integration of the two, all functions of the parietal lobe, may have endowed Homo sapiens with improved abilities for precise manipulative control of the fingers and held objects, especially those with compound parts. Parallel fMRI studies of humans and macaques have demonstrated betweenspecies differences in the visual processing of shape: Intraparietal cortex was more sensitive to 2D shape in monkeys than in humans, while regions sensitive to both shape and motion overlapped to a greater degree in humans than in monkeys. Other fMRI studies have found four regions sensitive to 2D shape and three regions representing central vision in humans, but only two shape-sensitive visual regions and one central representation region in macaques; this suggests that the anterior IPS in humans may lack a homologue in macaques, implying it may be evolutionarily new. By representing additional aspects of visual stimuli, these new IPS regions might have afforded Homo sapiens with finer control of their fingers and the objects they held, enabling the fabrication and skillful use of compound tools (e.g., see Orban 2011; Orban and Caruana 2014; Peeters et al. 2009, 2013).

An advantage in the manufacture and use of tools for Homo sapiens is suggested when their technologies are compared with those of Neandertals. Levallois, a challenging prepared-core technique often associated with Neandertals (Schlanger 1996), demonstrates that Neandertals were certainly capable of mastering difficult skills in manufacturing tools. Neandertals also produced composite tools, but such tools appear to have played a less prominent role in the Neandertal technical repertoire (Churchill 2001). This is consistent with Neandertal trauma patterns, which suggest that their habitual technique for hunting was close in, a thrusting technique that brought 
them dangerously close to the large animals that were their prey, rather than the safer at-distance techniques enabled by compound weapons (Berger and Trinkaus 1995; Trinkaus 1995), although Trinkaus has recently suggested alternative explanations including wounds that may have been caused by activities other than close hunting (Trinkaus 2012) This suggests that Neandertals may have been additionally limited by an inability to throw spears or aim stand-off weapons accurately (Coolidge and Overmann 2012; Holloway 1996). The apparent failure of the Neandertals to include stand-off weapons and techniques in their hunting suggests that they may have had limitations (relative to Homo sapiens) involving hand/movement control, vision, and spatial awareness and judgment (Coolidge and Overmann 2012).

Another important function of the IPS is its support of quantity judgments, an ability known as numerosity; the IPS contains neurons specialized to respond to quantity (see Coolidge and Overmann 2012 for an extensive review of this literature). In conjunction with expanded abilities for skillfully manipulating fingers and material objects (e.g., Peeters et al. 2013), parietal abilities for quantity appreciation may underlie both finger-counting and the expression of quantity in tangible form (Malafouris 2010). Finger-counting may appear in the archaeological record as early as 27,000 years ago; the use of fingers for counting at least as high as five is suggested by the nonrandom distribution of the short-long digits in the negative stencils at Cosquer Cave, Bouches-duRhône, Marseille, France, which have been dated to about 27,000 years ago (Rouillon 2006). Rouillon observed that only five of the 32 possible finger patterns were represented in the negative handprints at Cosquer, and he noted their similarity to modern finger-counting systems for integers (numbers 'one' through 'five', formed by cumulatively extending the thumb, index, major, ring, and smallest fingers), speculating that the Cosquer stencils may have formed a numeric code. Rouillon's interpretation is further supported when the Cosquer stencils are compared to the characteristics of modern finger-counting systems: The Cosquer stencils suggest an extendedfinger counting system proceeding sequentially across the hand from thumb (extended to form the integer 'one') to little finger (extended cumulatively with the other fingers and the thumb to form the integer 'five'), a comparison that may render non-numeric interpretations of the stencils less likely (see Overmann 2014). It should also be noted that parietal lobe expansion may not be without its negative consequences as a recent study by Bruner and Jacobs (2012) suggests that Alzheimer's disease may have its roots in a particular and unique parietal lobe susceptibility to the early neuronal changes and deterioration associated with the disease.

The emergence of material artifacts capable of instantiating number concepts may go back as far as 100,000 years and possibly represent the interaction of parietal judgments of quantity with abilities for sensorimotor finger control and association/integration. These include beads from Pinnacle Point and Blombos Cave, both Middle Stone Age (MSA) sites located in South Africa (d'Errico et al. 2005; Marean 2010; Vanhaeren et al. 2013). Beads with wear marks suggesting that they were strung together appear in the archaeological record of the African MSA soon after the expansion of the parietal lobe in Homo sapiens (Bruner 2003, 2004; Vanhaeren et al. 2013). Beads, of course, are not the only artifacts capable of instantiating number concepts, though many other candidates (e.g., notched sticks, knotted strings) might be less likely to preserve. When strung, beads possess inherent characteristics that are also components of natural number and which can act to scaffold the development of explicit concepts that are not themselves innate: Strung beads represent a one-dimensional series, the individuation of items, and an invariant sequence.

Strung beads may also be worn for social purposes, marking such things as social identity and status, making the use of strung beads for number concept instantiation ambiguous. Other 
possible material scaffolds with perhaps less ambiguity to their quantification purpose include later artifacts that appear to have been notched to represent quantity. These include the so-called counting devices found at Blanchard, Cellier, and Lartet about 28,000 years ago and the Tai plaque about 14,000 years ago (Coolidge and Overmann 2012). All of these are bones and stones modified with various notches and marks, possibly used for the purposes of quantifying trade equity, keeping track of hunting kills, or recording menstrual or lunar cycles. These and similar devices, along with the notched sticks, knotted strings, and clay tokens appearing much more recently in the archaeological record, appear to express embodied sensorimotor associations of numerical quantity in external material phenomena (Malafouris 2010). They perhaps constitute the earliest known emergence of numerical signs, providing insight about the development of symbolic thinking, as well as its timeline.

The neurons of the IPS do more than habituate to non-symbolic quantities (i.e., the quantities inherent in groups of objects). IPS neuronal habituation to non-symbolic quantity appears to transfer to adjacent neurons to support the recognition of symbolic quantities (i.e., quantities represented by symbols such as ' 3 ' or ' 27 '). Further, these functions may enable the IPS to understand other, nonnumeric symbols such as the letters of the alphabet. The IPS, particularly its horizontal segment (hIPS), activates during tasks involving ordinal relationships between numbers, relationships inherent in integers because they are arranged in a specified sequence (i.e., $1,2,3 .$. ) along a uniform dimension (i.e., each successive number is $n+1$ ). Ordinal comparisons of letters activate the same neural networks involved in quantity and number ordinality tasks, particularly the hIPS and IPS. The similar activation patterns do not necessarily mean the same neurons respond to both numerical and non-numerical ordinality, since other evidence suggests that IPS neurons are highly specialized for number functions. Because the hIPS activates during alphabetical order tasks, the IPS may support two levels of abstraction, a lower level linked to sensory mechanisms and a higher level involved in understanding symbols, with the higher-level abstraction realized by the hIPS in processing symbolic letters remaining closely linked to lowerlevel, sensory-based abstractive neural mechanisms because both are grounded in visuospatial representation This mechanism has been proposed as potential solution to the symbol grounding problem, the question of how arbitrary shapes, which lack intrinsic meaning in themselves, become intelligible symbolic representations through cognitive assignments of meaning; Coolidge and Overmann (2012) speculated that this mechanism would help connect the world of sense perception to the domain of concepts and in turn connect concepts to their expression and shared meaning as signs and symbols in material culture and language. See Dehaene (2011) and Dehaene and Brannon (2011) for overviews of this literature.

Parietal expansion in Homo sapiens would have entailed not only vertical height increases (globularization) but downward displacement of parietal cortex as well (Coolidge and Overmann 2012); a change that cannot be detected through morphometric analyses since it involves internal tissues generally invisible to such techniques (See Gunz et al. 2010; Neubauer et al. 2009, 2010 for a more detailed discussion of parietal globularization in humans, Neandertals, and nonhuman primates). However, encephalization is a process of expansion that does not exempt particular growth trajectories, though some are more constrained than others by brain pressure and tensions exerted by connective and biomechanical tensors. This suggests that parietal expansion would have entailed downward displacement in addition to the upward displacement causing increased vault height and globularization. Downward displacement would have collocated the IPS with the angular and supramarginal gyri of the inferior parietal lobe, key language centers implicated in abilities for figurative expressions (i.e., metaphor) and inner speech (Geva et al. 2011; 
Ramachandran 2004; Seghier 2012; Wynn and Coolidge 2011). These regions of the parietal lobe interact to process symbols for numbers: The IPS recruits number-specific neurons in both the angular and supramarginal gyri to support the appreciation and understanding of symbolic numbers, activation detected when adults perform symbolic number tasks. This interaction is perhaps also seen in the expression of numerical concepts in metaphoric language: Conceptual metaphors may be a central cognitive mechanism for the extension from numerosity to higher levels of mathematics and symbolization. An early artifact interpreted as representing metaphoric thinking (though not in a mathematical sense) is the Hohlenstein-Stadel figurine, about 32,000 years old; it perhaps represents symbolization of the metaphor relating conceptual similarities between people and lions (again, see Coolidge and Overmann 2012 for a review of the above literature and Wynn et al. 2009 for a discussion of the Hohlenstein-Stadel figurine).

Dehaene (2011) and Dehaene and Brannon (2011) have noted that the IPS is highly specialized for numbers, ordinal relationships, and abstraction, attributes that may support the recognition of symbols, not only symbols for numbers but non-numeric symbols such as letters as well. Enhanced parietal functions for abstraction, symbolic understanding, and language thus might have helped support the higher-level symbolic capabilities found in Homo sapiens in the Upper Paleolithic, attested to by cave art; exotic raw materials in blades; beads and ornaments made of teeth, shells, and ivory; and regional differences suggestive of cultural variation (Conneller 2011; Vanhaeren and d'Errico 2006; Woods 2011). This cultural and symbolic complexity appears to have little counterpart in the Neandertals beyond some use of pigment and shells for ornamentation (Zilhão et al. 2010).

\section{Summary}

The present analysis shows how paleoneurology, which focuses on brain structures and their evolution, is complemented by cognitive archaeology, which focuses on brain functions and their evolution. Cognitive archaeology infers psychology from behavioral traces in the archaeological record, as well as the fossil record, not just the skull but the entire physiology, which provides information on things like diet, habitat, and lifestyle. In addition to defining the scope of cognitive archaeology, we also reviewed its methods, criteria, and challenges.

We have noted the major cognitive leaps in hominid evolution. The first occurred with the transition to ground sleep in archaic humans about 1.8 million years ago; ground sleep would have yielded three specific benefits: threat simulation and priming, creativity, and procedural memory consolidation and enhancement. The second major leap invoked Baddeley's Working Memory hypothesis and the enhancement of working memory in Homo sapiens beginning about 200,000 years ago. We reviewed the archaeological evidence for enhanced executive functions, phonological storage, the visuospatial sketchpad, and the episodic buffer. The latter was proposed to be one of the key features of fully modern thinking in Homo sapiens, as it may serve not only a multi-modal integrative function between other components of working memory, affording verbal tagging of visual and spatial elements, but also providing a foundation for episodic memory and autonoetic consciousness, which enabled modern humans to travel subjectively and fluidly between past and future events. As a consequence of enhanced working memory, humans are able to construct future simulations and decide among alternatives, greatly enhancing behavioral flexibility. Further, this ability to construct alternative future models also suggests the emergence of a sense of self. 
Finally, if modern humans are characterized by parietal expansion and concomitant improvement to parietal functioning, then this informs a valid cognitive paradigm with which to view behavioral change in the archaeological record. Certainly, increased abilities to navigate and exploit territories, make and use tools, and count and measure are consistent with enhanced parietal functions of spatiality, the visual representation of shape, control of fingers, quantity appreciation, and symbolic understanding. In addition, if the epicenter of parietal expansion is the superior portion of the parietal lobes (where the intraparietal sulcus and precuneus are located), then this suggests that number and prospective memory may have played critical roles in the evolution of modern human thinking. Since the Neandertals lacked the same parietal expansion as that which characterizes Homo sapiens and their archaeological record suggests they were less flexible in behaviors and capabilities associated with parietal functioning, then the conclusion suggested is that parietal morphology has significant explanatory power for why the Neandertals went extinct and Homo sapiens flourished.

\section{References}

Aboitiz F, Aboitiz S, Garcia R (2010) The phonological loop: a key innovation in human evolution. Curr Anthropol 51:S55-S65

Adams AM, Gathercole S (2000) Limitations in working memory: implications for language development. Int J Lang Commun Disord 35:95-116

Addis DR, Wong AT, Schacter DL (2007) Remembering the past and imagining the future: common and distinct neural substrates during event construction and elaboration. Neuropsychologia 45:1363-1377

Allison T, Cicchetti DV (1976) Sleep in mammals: ecological and constitutional correlates. Science 194:732-734

Ambrose S (2010) Coevolution of composite-tool technology, constructive memory, and language: implications for the evolution of modern human behavior. In: Wynn T, Coolidge F (eds) Working memory: beyond language and symbolism. University of Chicago Press, Chicago

Antón SC (2003) Natural history of Homo erectus. Yearb Phys Anthropol 46:126-170

Antón SC, Swisher CC (2004) Early dispersals of Homo from Africa. Annu Rev Anthropol 33:271-296

Antón S, Leonard W, Robertson M (2002) An ecomorphological model of the initial hominid dispersal from Africa. J Hum Evol 43:773-785

Baddeley A, Hitch GJ (1974) Working memory. In: Bower GA (ed) Recent advances in learning and motivation. Academic Press, New York, pp 47-90

Baddeley A, Logie R (1999) Working memory: the multiple-component model. In: Miyake A, Shah P (eds) Models of working memory: mechanisms of active maintenance and executive control. Cambridge University Press, Cambridge, pp 28-61

Baddeley A (2000) The episodic buffer: a new component of working memory? Trends Cogn Sci 4:417-423

Baddeley A (2001) Is working memory working? Am Psychol 56:851-864

Baddeley A (2007) Working memory, thought, and action. Oxford University Press, Oxford 
Berger TD, Trinkaus E (1995) Patterns of trauma among the Neandertals. J Archaeol Sci 22:841-852

Berna F, Goldberg P, Horwitz LK, Brink J, Holt S, Bamford M, Chazan M (2012) Microstratigraphic evidence of in situ fire in the Acheulean strata of Wonderwerk Cave, Northern Cape province, South Africa. Proc Natl Acad Sci USA 109:E1215-E1220

Bleed P (1986) The optimal design of hunting weapons: maintainability or reliability? Am Antiq 51:737-747

Botha R (2008) Prehistoric shell beads as a window on language evolution. Lang Commun 28:197-212

Botha R (2012) Inferring modern language from ancient objects. In: Tallerman M, Gibson KR (eds) The Oxford handbook of language evolution. Oxford University Press, Oxford, pp 312-393

Bramble DM, Lieberman DE (2004) Endurance running and the evolution of Homo. Nature 432:345-352

Braun DR, Plummer T, Ditchfield P, Ferraro JV, Maina D, Bishop LC et al (2008) Oldowan behavior and raw material transport: perspectives from the Kanjera Formation. $J$ Archaeol Sci 35:2329-2345

Bruner E (2003) Fossil traces of the human thought: paleoneurology and the evolution of the genus Homo. Rivista di Antropologia, J Anthropol Sci 81:29-56

Bruner E (2004) Geometric morphometrics and paleoneurology: brain shape evolution in the genus Homo. J Hum Evol 47:279-303

Bruner E (2010) Morphological differences in the parietal lobes within the human genus: a neurofunctional perspective. Curr Anthropol 51:S77-S88

Bruner E, Holloway RL (2010) A bivariate approach to the widening of the frontal lobes in the genus Homo. J Hum Evol 58:138-146

Bruner E, de la Cuétara JM, Holloway RL (2011) A bivariate approach to the variation of the parietal curvature in the genus Homo. Anat Rec 294:1548-1556

Bruner E, Jacobs HI (2012) Alzheimer's disease: the downside of a highly evolved parietal lobe? J Alzheimers Dis 35:227-240

Bruner E, De Lázaro GR, De la Cuétara JM, Martín-Loeches M, Colom R et al. (2014) Midsagittal brain variation and MRI shape analysis of the precuneus in adult individuals. $J$ Anat 224:1-10

Bruner E, Manzi G, Arsuaga JL (2003) Encephalization and allometric trajectories in the genus Homo: evidence from the Neandertal and modern lineages. Proc Natl Acad Sci USA 100:15335-15340

Cachel S, Harris JWK (1998) The lifeways of Homo erectus inferred from archaeology and evolutionary ecology: a perspective from East Africa. In: Petraglia MD, Korisettar R (eds) Early human behavior in global context: the rise and diversity of the Lower Palaeolithic record. Routledge, London, pp 108-132

Cairney SA, Durrant SJ, Hulleman J, Lewis PA (2014) Targeted memory reactivation during slow wave sleep facilitates emotional memory consolidation. Sleep 37:701-707 
Caruana MV, d'Errico F, Backwell L (2013) Early hominin social learning strategies underlying the use and production of bone and stone tools. In: Sanz CM, Call J, Boesch C (eds) Tool use in animals: cognition and ecology. Cambridge University Press, Cambridge, pp 242-285

Cavanna AE, Trimble MR (2006) The precuneus: a review of its functional anatomy and behavioral correlates. Brain 129:564-583

Chiappe DL, Chiappe P (2007) The role of working memory in metaphor production and comprehension. J Mem Lang 56:172-188

Churchill SE (2001) Hand morphology, manipulation, and tool use in Neandertals and early modern humans of the Near East. Proc Natl Acad Sci USA 98:2953-2955

Clayton NS, Bussey TJ, Dickinson A (2003) Can animals recall the past and plan for the future? Nat Rev Neurosci 4:685-691

Collette F, Van der Linden M (2002) Brain imaging of the central executive component of working memory. Neurosci Biobehav Rev 26:102-125

Conneller C (2011) An archaeology of materials: substantial transformations in early prehistoric Europe. Routledge, New York

Coolidge FL, Overmann KA (2012) Numerosity, abstraction, and the emergence of symbolic thinking. Curr Anthropol 53:204-225

Coolidge FL, Wynn T (2001) Executive functions of the frontal lobes and the evolutionary ascendancy of Homo sapiens. Camb Archaeol J 11:255-260

Coolidge FL, Wynn T (2005) Working memory, its executive functions, and the emergence of modern thinking. Camb Archaeol J 15:5-26

Coolidge FL (2007) The working memory account of Neandertal cognition-How phonological storage capacity may be related to recursion and the pragmatics of modern speech. $J$ Hum Evol 52:707-710

Coolidge FL, Wynn T (2009) The rise of Homo sapiens: the evolution of modern thinking. Wiley, Hoboken

Coolidge FL, Wynn T (2012) Cognitive prerequisites for a language of diplomacy. In: Tallerman M, Gibson KR (eds) The Oxford handbook of language evolution. Oxford University Press, Oxford, pp 216-223

Coolidge FL, Overmann KA, Wynn T (2011) Recursion: what is it, who has it, and how did it evolve? Wiley Interdiscip Rev Cogn Sci 2:547-554

Culham JC, Kanwisher NG (2001) Neuroimaging of cognitive functions in human parietal cortex. Cogn Neurosci 11:157-163

d'Errico F, Henshilwood C, Vanhaeren M, Van Niekerk K (2005) Nassarius kraussianus shell beads from Blombos Cave: evidence for symbolic behaviour in the middle stone age. $J$ Hum Evol 48:3-24

Davidson I, Noble W (1989) The archaeology of perception: traces of depiction and language. Curr Anthropol 30:125-155 
Davidson I, Noble W (1993) Tools and language in human evolution. In: Gibson K, Ingold T (eds) Tools, language, and cognition in human evolution. Cambridge University Press, Cambridge, pp 263-288

Dehaene S (2011) The number sense, 2nd edn. Oxford University Press, New York

Dehaene S, Brannon EM (Eds) (2011) Space, time, and number: searching for the foundations of mathematical thought. Academic Press, New York

De Smet HJ, Paquier P, Verhoeven J, Mariën P (2013) The cerebellum: its role in language and related cognitive and affective functions. Brain Lang 127:334-342

Domínguez-Rodrigo M, Pickering TR, Bunn HT (2010) Configurational approach to identifying the earliest hominin butchers. Proc Natl Acad Sci USA 107:20929-20934

Donald M (1991) Origins of the modern mind: three stages in the evolution of culture and cognition. Harvard University Press, Cambridge

Dunbar RIM (2003) The social brain: mind, language, and society in evolutionary perspective. Annu Rev Anthropol 32:163-181

Fernández-Laso MC, Navarro MGC, García-Antón MD, Rivals F (2011) Territorial mobility of Neanderthal groups: a case study from level M of Abric Romaní (Capellades, Barcelona, Spain). In: Conard NJ, Richter J (eds) Neanderthal lifeways, subsistence and technology: 150 years of Neanderthal study. Springer, Dordrecht, pp 187-202

Franklin MS, Zyphur MJ (2005) The role of dreams in the evolution of the human mind. Evol Psychol 3:59-78

Fruth B, Hohmann G (1996) Nest building behavior in the great apes: the great leap forward? In: McGrew WC, Marchant LF, Nishida T (eds) Great ape societies. Cambridge University Press, Cambridge, pp 225-239

Gais S, Plihal W, Wagner U, Born J (2000) Early sleep triggers memory for early visual discrimination skills. Nat Neurosci 3:1335-1339

García-Antón MD, Granda LM, Navarro MGC (2011) Level G of Las Fuentes de San Cristóbal (Southern Pyrenees, Spain): availability of lithic resources and territory management. In: Conard NJ, Richter J (eds) Neanderthal lifeways, subsistence and technology: 150 years of Neanderthal Study. Springer, Dordrecht, pp 203-219

Gazzaniga M, Ivry R, Mangun G (2013) Cognitive neuroscience, 4th edn. W.W. Norton \& Co, New York

Geva S, Jones PS, Crinion JT, Price CJ, Baron J-C, Warburton EA (2011) The neural correlates of inner speech defined by voxel-based lesion symptom mapping. Brain 134:3071-3082

Graves RR, Lupo AC, McCarthy RC, Wescott DJ, Cunningham DL (2010) Just how strapping was KNM-WT 15000? J Hum Evol 59:542-554

Gunz P, Neubauer S, Maureille B, Hublin JJ (2010) Brain development after birth differs between Neanderthals and modern humans. Curr Biol 20:R921-R922

Hartmann E (1998) Dreams and nightmares: the new theory on the origin and meaning of dreams. Plenum Press, New York 
Hauser MD, Chomsky N, Fitch WT (2002) The faculty of language: what is it, who has it, and how did it evolve? Science 298:1569-1579

Hazy T, Frank M, O’Reilly R (2006) Banishing the homunculus: making working memory work. Neuroscience 139:105-118

Henshilwood C, Dubreuil B (2009) Reading the artefacts: Gleaning language skills from the Middle Stone Age in southern Africa. In: Botha R (ed) The cradle of language, Stellenbosch, South Africa, pp 41-63

Henshilwood CS, d'Errico F, Vanhaeren M, van Niekerk K, Jacobs Z (2004) Middle Stone Age shell beads from South Africa. Science 304:404

Hodgson D (2009) Evolution of the visual cortex and the emergence of symmetry in the Acheulean techno-complex. CR Palevol 8:93-97

Holloway RL (1996) Toward a synthetic theory of human brain evolution. In: Changeaux JP, Chavaillon J (eds) Origins of the human brain. Clarendon Press, Oxford, pp 42-54

Kane M, Engle R (2002) The role of prefrontal cortex in working-memory capacity, executive attention, and general fluid intelligence: an individual-differences perspective. Psychon Bull Rev 9:637-671

Karni A, Tanne D, Rubenstein BS, Askenasy JJ, Sagi D (1994) Dependence on REM sleep of overnight improvement of a perceptual skill. Science 265:679-682

Keller C, Keller J (1996) Cognition and tool use: the blacksmith at work. Cambridge University Press, Cambridge

Klein R (2000) Archeology and the evolution of human behavior. Evol Anthropol 9:17-36

Koenigs M, Barbey AK, Postle BR, Grafman J (2009) Superior parietal cortex is critical for the manipulation of information in working memory. J Neurosci 29:14980-14986

Kohn M, Mithen S (1999) Handaxes: products of sexual selection? Antiquity 73:518-526

Koziol LF, Budding DE, Chidekel D (2010) Adaptation, expertise, and giftedness: towards an understanding of cortical, subcortical, and cerebellar network contributions. Cerebellum 9:499-529

Krippner S, Hughes W (1970) Genius at work. Psychol Today June 40-43 Land MF (2014) Do we have an internal model of the outside world? Philos Trans R Soc B 369:20130045

Lezak M (1982) The problem of assessing executive functions. Int J Psychol 17:281-297

Lieberman DE, Bramble DM, Raichlen DA, Shea JJ (2009) Brains, brawn and the evolution of human endurance running capabilities. In: Grine FE, Fleagle JG, Leakey RE (eds) The first humans: origin and early evolution of the genus Homo. Springer, New York pp 77-98

Lombard M, Haidle M (2012) Thinking a bow-and-arrow set: cognitive implications of Middle Stone Age bow and stone-tipped arrow technology. Camb Archaeol J 22:237-264

Lou HC, Luber B, Crupain M, Keenan JP, Nowak M, Kjaer TW et al (2004) Parietal cortex and representation of the mental self. Proc Natl Acad Sci USA 101:6827-6832

Malafouris L (2008) Beads for a plastic mind: the ‘Blind Man’s Stick’ (BMS) hypothesis and the active nature of material culture. Camb Archaeol J 18:401-414 
Malafouris L (2010) Grasping the concept of number: how did the sapient mind move beyond approximation? In: Renfrew C, Morley I (eds) The archaeology of measurement: comprehending heaven, earth and time in ancient societies. Cambridge University Press, Cambridge, pp 35-42

Malafouris L (2013) How things shape the mind: A theory of material engagement. MIT Press, Cambridge

Malcolm-Smith S, Solms M (2004) Incidence of threat in dreams: a response to Revonsuo's threat simulation theory. Dreaming 14:220-229

Marean C (2010) Introduction to the special issue: the Middle Stone Age at Pinnacle Point Site 13B, a coastal cave near Mossel Bay (Western Cape Province, South Africa). J Hum Evol 59:231-233

Martin-Ordas G, Call J (2013) Episodic memory: a comparative approach. Front Behav Neurosci $7: 1-13$

McGrew WC (1992) Chimpanzee material culture. Cambridge University Press, Cambridge

McGrew WC (2004) The cultured chimpanzee: reflections on cultural primatology. Cambridge University Press, Cambridge

McPherron SP (2000) Handaxes as a measure of the mental abilities of early hominids. J Archaeol Sci 27:655-663

McPherron SP, Alemseged Z, Marean CW, Wynn JG, Reed D, Geraads D et al. (2010) Evidence for stone-tool-assisted consumption of animal tissues before 3.39 million years ago at Dikika, Ethiopia. Nature 466:857-860

Mithen S (1999) Imitation and cultural change: a view from the Stone Age, with specific reference to the manufacture of handaxes. In: Box HO, Gibson KR (eds) Mammalian social learning: comparative and ecological perspectives. Cambridge University Press, Cambridge, pp 389-399

Miyake A, Shah P (1999) Models of working memory: mechanisms of active maintenance and executive control. Cambridge University Press, Cambridge

Neubauer S, Gunz P, Hublin JJ (2009) The pattern of endocranial ontogenetic shape changes in humans. J Anat 215:240-255

Neubauer S, Gunz P, Hublin JJ (2010) Endocranial shape changes during growth in chimpanzees and humans: a morphometric analysis of unique and shared aspects. J Hum Evol 59:555-566

Noble W, Davidson I (1996) Human evolution, language, and mind: a psychological and archaeological inquiry. Cambridge University Press, Cambridge

O’Connell JF, Allen J (2004) Dating the colonization of Sahul (Pleistocene Australia-New Guinea): a review of recent research. J Archaeol Sci 31:835-853

Ogawa A, Yamazaki Y, Ueno K, Cheng K, Iriki A (2010) Inferential reasoning by exclusion recruits parietal and prefrontal cortices. Neuroimage 52:1603-1610

Ohayon MM, Carskadon MA, Guilleminault C, Vitiello MV (2004) Meta-analysis of quantitative sleep parameters from childhood to old age in healthy individuals: developing normative sleep values across the human lifespan. Sleep 27:1255-127 
Orban GA (2011) The extraction of 3D shape in the visual system of human and nonhuman primates. Annu Rev Neurosci 34:361-388

Orban GA, Caruana F (2014) The neural basis of human tool use. Front Psychol 5:1-12

Osaka N, Logie R, d'Esposito M (eds) (2007) The cognitive neuroscience of working memory. Oxford University Press, Oxford

Oswalt W (1976) An anthropological analysis of food-getting technology. Wiley, New York

Overmann KA (2014) Finger-counting in the Upper Paleolithic. Rock Art Research 31:63-80

Peeters RR, Simone L, Nelissen K, Fabbri-Destro M, Vanduffel W, Rizzolatti G et al (2009) The representation of tool use in humans and monkeys: common and uniquely human features. J Neurosci 29:11523-11539

Peeters RR, Rizzolatti G, Orban GA (2013) Functional properties of the left parietal tool use region. Neuroimage 78:83-93

Ramachandran VS (2004) A brief tour of human consciousness: from impostor poodles to purple numbers. Pi Press, New York

Reuland E (2005) On the evolution and genesis of language: the force of imagination. Lingue $e$ Linguaggio 4:81-110

Revonsuo A, Valli K (2000) Dreaming and consciousness: testing the threat simulation theory of the function of dreaming. Psyche 6 [Internet]. 2000 [cited 2014 January 11]. http://www. theassc.org/files/assc/2467.pdf

Revonsuo A (2000) The reinterpretation of dreams: an evolutionary hypothesis of the function of dreaming. Behav Brain Sci 23:793-1121

Roebroeks W, Kolen J, Rensink E (1988) Planning depth, anticipation and the organization of Middle Palaeolithic technology: “Archaic natives” meet Eve's descendants. Helenium 28:17-34

Rouillon A (2006) Au Gravettien, dans la grotte Cosquer (Marseille, Bouches-du-Rhône), l’Homme a-t-il compté sur ses doigts? L'anthropologie 110:500-509

Ruff CB (1991) Climate and body shape in hominid evolution. J Hum Evol 21:81-104

Ruff CB (1993) Climatic adaptation and hominid evolution: the thermoregulatory imperative. Evol Anthropol 2:53-60

Sabater Pi J, Veá JJ, Serrallonga J (1997) Did the first hominids build nests? Curr Anthropol 38:914-916

Savage-Rumbaugh ES, Toth N, Schick K (2007) Kanzi learns to knap stone tools. In: Washburn DA (ed) Primate perspectives on behavior and cognition. American Psychological Association, Washington, pp 279-291

Schick K, Toth N (2006) An overview of the Oldowan industrial complex: the sites and the nature of their evidence. In: Toth N, Schick K (eds) The Oldowan: case studies into the earliest stone age. Stone Age Institute Press, Gosport, pp 3-42

Schick K, Toth N (2009) The cutting edge: new approaches to the archaeology of human origins. Stone Age Institute Press, Gosport 
Schlanger N (1996) Understanding Levallois: lithic technology and cognitive archaeology. Camb Archaeol J 6:231-254

Segal DL, Coolidge FL, Rosowsky E (2006) Personality disorders and older adults: diagnosis, assessment, and treatment. John Wiley \& Sons, Hoboken

Seghier ML (2012) The angular gyrus: multiple functions and multiple subdivisions. Neuroscientist 19:1-19

Semaw S, Renne P, Harris JWK, Feibel CS, Bernor RL, Fesseha N, Mowbray K (1997) 2.5million-year-old stone tools from Gona, Ethiopia. Nature 385:333-336

Semaw S, Rogers MJ, Quade J, Renne PR, Butler RF, Dominguez-Rodrigo M, Simpson SW (2003) 2.6-million-year-old stone tools and associated bones from OGS-6 and OGS-7, Gona, Afar, Ethiopia. J Hum Evol 45:169-177

Semaw S, Rogers M, Stout D (2009) Insights into late Pliocene lithic assemblage variability: the East Gona and Ounda Gona South Oldowan archaeology (2.6 million years ago), Afar, Ethiopia. In: Schick K, Toth $\mathrm{N}$ (eds) The cutting edge: new approaches to the archaeology of human origins. Stone Age Institute Press, Gosport, pp 211-246

Sherratt A (1997) Climatic cycles and behavioural revolutions: the emergence of modern humans and the beginning of farming. Antiquity 71:187-271

Spinapolice EE (2012) Raw material economy in Salento (Apulia, Italy): new perspectives on Neanderthal mobility patterns. J Archaeol Sci 39:680-689

Spoor F, Zonneveld F (1998) Comparative review of the human bony labyrinth. Yearb Phys Anthropol 41:211-251

Stanley SM (1992) An ecological theory for the origin of Homo. Paleobiology 18:237-257

Stickgold R, James L, Hobson JA (2000) Visual discrimination learning requires sleep after training. Nat Neurosci 2:1237-1238

Steudel-Numbers K (2006) Energetics in Homo erectus and other early hominins: the consequences of increased lower limb length. J Hum Evol 51:445-453

Stout D (2002) Skill and cognition in stone tool production. Curr Anthropol 43:693-722

Stout D, Chaminade T (2007) The evolutionary neuroscience of tool making. Neuropsychologia 45:1091-1100

Stout D, Passingham R, Frith C, Apel J, Chaminade T (2011) Technology, expertise, and social cognition in human evolution. Eur J Neurosci 33:1328-1338

Stout D, Toth N, Schick K, Chaminade T (2008) Neural correlates of Early Stone Age toolmaking: technology, language, and cognition in human cognition. Philos Trans R Soc Lond B Biol Sci 363:1939-1949

Stout D, Toth N, Schick K, Stout J, Hutchins G (2000) Stone tool-making and brain activation: positron emission tomography (PET) studies. J Archaeol Sci 27:1215-1223

Suddendorf T, Corballis MC (2007) The evolution of foresight: what is mental time travel, and is it unique to humans? Behav Brain Sci 30:299-351 
Tononi G, Cirelli C (2014) Sleep and the price of plasticity: from synaptic and cellular homeostasis to memory consolidation and integration. Neuron 81:12-34

Toth N (1985) The Oldowan reassessed: a closer look at early stone artifacts. J Archaeol Sci 12:101-120

Toth N (1987) Behavioral inferences from Early Stone Age artifact assemblages: an experimental model. J Hum Evol 16:763-787

Toth N, Schick K (2009) The Oldowan: the tool making of early hominins and chimpanzees compared. Annu Rev Anthropol 38:289-305

Toth N, Schick K (eds) (2006) The Oldowan: case studies into the earliest stone age. Stone Age Institute Press, Gosport

Trinkaus E (1995) Neanderthal mortality patterns. J Archaeol Sci 22:121-142

Trinkaus E (2012) Neandertals, early modern humans, and rodeo riders. J Archaeol Sci 39:3691-3693

Tulving E (2002) Episodic memory: from mind to brain. Annu Rev Psychol 53:1-25

Twomey T (2013) The cognitive implications of controlled use of fire. Camb Archaeol J 23:113-128

Valli K, Revonsuo A, Pälkäs O, Ismahil KH, Ali KJ, Punamäki R-L (2005) The threat simulation theory of the evolutionary function of dreaming: evidence from dreams of traumatized children. Conscious Cogn 14:188-218

Van de Castle RL (1983) Animal figures in fantasy and dreams. In: Kacher A, Beck A (eds) New perspectives on our lives with companion animals. University of Pennsylvania Press, Philadelphia, pp 148-173

Vandervert LR (2003a) How working memory and cognitive modeling functions of the cerebellum contribute to discoveries in mathematics. New Ideas Psychol 21:159-175

Vandervert LR (2003b) The neurophysiological basis of innovation. In: Shavinina LV (ed) The international handbook on innovation. Elsevier Science, Oxford, pp 17-30

Vandervert LR (2009) The appearance of the child prodigy 10,000 years ago: an evolutionary and developmental explanation. J Mind Behav 30:15-32

Vandervert LR (2011) The evolution of language: the cerebro-cerebellar blending of visual-spatial working memory with vocalizations. J Mind Behav 32:317-332

Vandervert LR, Schimpf PH, Liu H (2007) How working memory and the cerebellum collaborate to produce creativity and innovation. Creat Res J 19:1-18

Vanhaeren M, d'Errico F (2006) Aurignacian ethno-linguistic geography of Europe revealed by personal ornaments. J Archaeol Sci 33:1105-1128

Vanhaeren M, d'Errico F, Van Niekerk K, Henshilwood C, Erasmus R (2013) Thinking strings: additional evidence for personal ornament use in the Middle Stone Age at Blombos Cave, South Africa. J Hum Evol 64:500-517

Wadley L (2010) Were snares and traps used in the Middle Stone Age and does it matter? a review and a case study from Sibudu, South Africa. J Hum Evol 58:179-192 
Wadley L, Hodgskiss T, Grant M (2009) Implications for complex cognition from the hafting of tools with compound adhesives in the Middle Stone Age, South Africa. Proc Natl Acad Sci USA 106:9590-9594

Wagner U, Gais S, Haider H, Verleger R, Born J (2004) Sleep inspires insight. Nature 427:352-355

Weaver AH (2005) Reciprocal evolution of the cerebellum and neocortex in fossil humans. Proc Natl Acad Sci USA 102:3576-3580

Whiten A, Byrne R (1991) The emergence of meta-representation in human ontogeny and primate phylogeny. In: Whiten A (ed) Natural theories of mind. Blackwell, Oxford, pp 267-281

Whiten A, Ham R (1992) On the nature and evolution of imitation in the animal kingdom: reappraisal of a century of research. In: Slater P, Rosenblatt J, Beer J, Milinski M (ed) Advances in the study of behavior, Academic Press, New York, vol 21, pp 239-283

Winson J (1990) The meaning of dreams. Sci Am 263:89-96

Wong K (2006) Lucy’s baby. Sci Am 295:78-85

Woods AD (2011) The effects of lithic raw material quality on Aurignacian blade production at Abri Cellier. Doctoral dissertation, University of Iowa. http://ir.uiowa.edu/etd/1111

Wynn T (1981) The intelligence of Oldowan hominids. J Hum Evol 10:529-541

Wynn T (1995) Handaxe enigmas. World Archaeol 27:10-24

Wynn T (2002) Archaeology and cognitive evolution. Behav Brain Sci 25:389-438

Wynn T (2009a) Hafted spears and the archaeology of mind. Proc Natl Acad Sci USA 106:9544-9545

Wynn T (2009b) Whither evolutionary cognitive archaeology? Afterword. In: de Beaune S, Coolidge FL, Wynn T (eds) Cognitive archaeology and human evolution. Cambridge University Press, Cambridge, pp 145-149

Wynn T, Coolidge FL (2003) The role of working memory in the evolution of managed foraging. Before Farming 2:1-16

Wynn T, Coolidge FL (2010) Beyond symbolism and language: an introduction to supplement 1, working memory. Curr Anthropol 51(Supplement1):S5-S16

Wynn T, Coolidge FL (2011) The implications of the working memory model for the evolution of modern cognition. Int $J$ Evol Biol [Internet]. 2011 [cited 2014 January 11]; Article ID 741357, p 12. doi:10.4061/2011/741357

Wynn T, Coolidge FL (2012) How to think like a Neandertal. Oxford University Press, Oxford

Wynn T, Coolidge F, Bright M (2009) Hohlenstein-Stadel and the evolution of human conceptual thought. Camb Archaeol J 19(1):73-83

Wynn T, Hernandez-Aguilar RA, Marchant L, McGrew WC (2011) “An ape's view of the Oldowan’' revisited. Evol Anthropol 20:181-197

Zilhão J, Angelucci DE, Badal-Garcia E, d'Errico F, Daniel F, Dayet L, Zapata J (2010) Symbolic use of marine shells and mineral pigments by Iberian Neandertals. Proc Natl Acad Sci USA 107:1023-1028 